ЖДАНОВСКИХ Родион Михайлович - аспирант кафедры мировой экономики Российского экономического университета им. Г.В. Плеханова (117997, Россия, г. Москва, Стремянный пер., 36; rody1993@rambler.ru)

\title{
ПОВЫШЕНИЕ НАДЕЖНОСТИ И СТАБИЛЬНОСТИ ГАЗОВОГО ЭКСПОРТА ИЗ РОССИИ В СТРАНЫ ДАЛЬНЕГО ЗАРУБЕЖЬЯ
}

Аннотация. В статье автор, используя вероятностную методику расчета, подтверждает, что надежность и стабильность российского газового экспорта в дальнее зарубежье можно повысить как применяя нетрадиционные газопроводные маршруты, так и расширяя производство и сбыт сжиженного природного газа.

Ключевые слова: Российская Федерация, инфраструктура, вероятность безотказного функционирования, надежность, сжиженный природный газ

$\mathrm{P}$ оссийская Федерация на современном этапе является крупнейшим мировым экспортером газа. Так, ее поставки в 2017 г. только в европейские страны и Турцию составили 194,4 млрд куб. м «голубого топлива» 1 , а в 2018 г. его экспорт может достичь 204 млрд куб. м.

Основным видом транспортировки отечественного природного газа (ПГ) как по российской территории, так и через зарубежные страны является трубопроводная подача. Исторически сложилось так, что основные транзитные маршруты экспорта российского «голубого топлива» в Европу проходили через Украину. И даже в настоящее время, после ввода в строй магистрального газопровода «Ямал-Европа», проложенного в европейские страны через Белоруссию, газопровода «Северный поток-1», проходящего из РФ в Германию через Балтийское море, и газотранспортной системы «Голубой поток», проложенной в Турцию через Черное море, транзит российского газа в Европу через территорию Украины является превалирующим. Например, в 2017 г. через Украину в европейские страны по магистральным трубопроводным системам было подано 93,5 млрд куб. м отечественного газа, что составляет около половины всего российского газового экспорта в эти страны ${ }^{2}$.

Однако газовый транзит из РФ в Европу через украинскую территорию осложняется как технологическими и экономическими, так и политическими факторами [Гладков 2014; 2017а; 2017б; 2018а; 2018б]. В настоящее время украинская газотранспортная система в достаточной степени изношена и нуждается в серьезной модернизации, на которую требуются значительные финансовые средства, которых на Украине сейчас нет. Однако это увеличивает вероятность возникновения аварий на украинских газопроводах. Кроме того, украинское правительство постоянно повышает плату за транзит газа по территории Украины, а также выставляет российскому Газпрому различные финансовые претензии на значительные валютные суммы. Все это вместе взятое осложняется еще и серьезными политическими разногласиями между руководством обоих государств. В таких условиях можно поставить под сомнение достаточ-

\footnotetext{
* Научный руководитель доктор экономических наук, профессор И.С. Гладков.

1 См.: Динамика реализации газа в Европу. - ООО «Газпром экспорт». Доступ: http://www. gazpromexport.ru/statistics/ (проверено 05.12.2018).

2 Украина заявила о рекордных показателях транзита газа в 2017 году. - Pravda.ru. Доступ: https:// www.pravda.ru/news/economics/03-01-2018/1364624-ukraina-0/ (проверено 05.12.2018).
} 
ную степень надежности и стабильности газового экспорта из РФ в Европу через Украину.

Всю газотранспортную систему, проложенную из Западной Сибири через Украину в европейские страны, можно условно разделить на три участка. Первый участок проходит по российской территории до границы с Украиной, второй участок - по украинской земле и третий пролегает через восточноевропейские страны в государства Центральной и Западной Европы. Надежность газового транзита на первом участке магистральных коммуникаций определяется только технологическими факторами и является высокой, т.к. транзит эффективно резервируется.

Обозначим вероятность безотказного функционирования российского участка магистральных газовых коммуникаций за время $t$ через $P_{1}(t)$. Ее можно оценить как $P_{1}(t)=0,99$, т.е. весьма высокую. Вероятность безотказного функционирования третьего участка газотранспортной системы, проходящей через восточноевропейские страны, за время $t$ обозначим как $P_{3}(t)$. Можно считать, что сейчас надежность работы газопроводов на третьем участке является высокой, и $P_{3}(t)=0,99$.

Самым малонадежным участком системы газопроводов, проходящих из РФ в Европу, является второй, пролегающий через Украину (в силу ряда рассмотренных выше причин). Вероятность безотказного функционирования за время $t$ второго участка обозначим через $P_{2}(t)$ и, считая ее невысокой, определим как $P_{2}(t)=0,95$. Тогда вероятность безотказной работы на всех трех участках газотранспортной системы, по которой осуществляется транзит российского газа в Европу, можно найти из формулы $P_{1 n}(t)=\prod_{i=1}^{n} P_{i}(t)$,

где $\Pi^{n}{ }_{i=1}$ означает произведение $n$ значений $P_{i}(t)$,

$i$ - это $i$-й участок газотранспортной системы.

В нашем случае рассмотрены три участка, поэтому $n=3$, и тогда $\prod_{i=1}^{3} P_{i}(t)=P_{1}(t) \cdot P_{2}(t) \cdot P_{3}(t)$ [Перроте, Сторчак 1976: 98]. Вероятность безотказного функционирования всей газотранспортной системы, идущей из РФ в Европу через Украину, численно равна $P_{1 n}(t)=0,99 \cdot 0,95 \cdot 0,99=0,931$. Эта величина говорит о недостаточной надежности работы системы.

В связи с негативными факторами, значительно снижающими надежность и стабильность экспорта российского газа через Украину, правительство РФ и компания «Газпром» стали искать иные пути для его поставок в европейские страны. В настоящее время, несмотря на противодействие США и ряда их союзников, ускоренными темпами ведется строительство второй очереди газотранспортной системы, пролегающей между РФ и Германией по дну Балтийского моря, под наименованием «Северный поток - 2». После ввода ее в эксплуатацию пропускная способность магистралей «Северный поток - 1» и «Северный поток - 2» составит в год 110 млрд куб. м газа, который будет поставляться в Германию при невысокой стоимости транзита.

Одновременно осуществляется интенсивное возведение двухпроводной газотранспортной системы из РФ в Турцию, прокладываемой по дну Черного моря, под наименованием «Турецкий поток» с ежегодной пропускной способностью до 31,5 млрд куб. м газа. Половину объема этого «голубого топлива» будет потреблять Турция, а другая половина будет направляться в страны Южной и Юго-Восточной Европы. Таким образом, после введения в строй газопроводов «Северный поток - 2» и «Турецкий поток» Газпром сможет поставлять в Турцию и европейские страны в обход Украины более 190 млрд куб. м газа в год с приемлемой надежностью его экспорта.

Но при всем этом трубопроводные системы привязывают страну - газового экспортера лишь к определенным государствам-потребителям, куда проложены газовые магистрали. И если по каким-либо причинам газовые потреби- 
тели отказываются приобретать это топливо, то заменить их стране-экспортеру сложно. С этой точки зрения экспорт сжиженного природного газа (СПГ) является значительно более гибким и надежным. СПГ, как и нефть, можно поставлять во многие регионы мира, меняя при необходимости покупателей. Вместо долгосрочных контрактов на газовые поставки по трубопроводным системам для продаж СПГ можно использовать спотовые контракты, а также фьючерсные и форвардные поставки.

В настоящее время РФ значительно отстает в производстве и продаже сжиженного газа от многих стран мира [Ждановских 2017: 130]. К началу 2019 г. производственные мощности по производству СПГ в РФ несколько превысят 26 млн т в год, в то время как общемировые мощности по сжижению газа к марту 2018 г. уже достигли 369 млн т в год ${ }^{1}$. И хотя себестоимость производства и транспортировки СПГ превышает стоимость подачи ПГ по трубопроводам, возможности поставок СПГ во все регионы мира и их гибкость оправдывают его более высокую стоимость. Поэтому только определенное сочетание трубопроводных газовых поставок с продажей значительных объемов СПГ в страны Азиатско-Тихоокеанского региона, безусловно, повысит надежность и стабильность российского газового экспорта.

\title{
Список литературы
}

Гладков И.С. 2014. Новый вектор внешнеторговых связей Российской Федерации? - Власть. № 11. С. 68-71.

Гладков И.С. 2017а. Динамика и структура внешнеторговых связей Европейского союза на этапе последнего его расширения. - Международная торговля и торговая политика. № 4(12). С. 6-22.

Гладков И.С. 2017б. Внешнеторговые связи Европейского союза на современном этапе: «эффект черепахи». - Власть. Т. 25. № 10. С. 105-111.

Гладков И.С. 2018а. Внешняя торговля России в 2017 году: разворот на взлет. - Власть. Т. 26. № 3. С. 38-46.

Гладков И.С. 2018б. Международная торговля в 2017 году: снова рост, но перспективы не обнадеживают. - Власть. Т. 26. № 5. С. 77-84.

Ждановских Р.М. 2017. Текущая конъюнктура в сфере экспорта российского сжиженного газа на базе инновационных технологий. - Власть. Т. 25. № 8. C. $129-131$.

Перроте А.И., Сторчак М.А. 1976. Вопросы надежности РЭА. М.: Советское радио. $184 \mathrm{c}$.

ZHDANOVSKIH Rodion Mikhailovich, postgraduate student at the Chair of World Economy, Plekhanov Russian University of Economics (36 Stremyanniy Lane, Moscow, Russia, 117997; rody1993@rambler.ru)

\section{IMPROVING THE RELIABILITY AND STABILITY OF GAS EXPORT FROM RUSSIA TO THE FAR-ABROAD COUNTRIES}

\begin{abstract}
In the article, the author using the probabilistic calculation method confirms that the reliability and safety of Russian gas exports to non-CIS countries can be improved by using both unconventional gas pipeline routes and expanding the production and marketing of liquefied natural gas.

Keywords: Russian Federation, infrastructure, probability of reliable operation, reliability, liquefied natural gas
\end{abstract}

\footnotetext{
12018 World LNG Report - International Gas Union. Доступ: https://www.igu.org/sites/default/files/ node-document-field_file/IGU_LNG_2018_0.pdf (проверено 15.12.2018).
} 